\title{
Presentación del Monográfico
}

\section{PUEBLOS INDÍGENAS Y CAPITALISMO: ¿QUÉ JUEGO JUGAR Y CON QUÉ REGLAS?}

Este monográfico de la Revista Internacional de Pensamiento Político (RIPP), dedicado a los pueblos indígenas surge de la mesa redonda "Derechos de los pueblos indígenas, lo común y la Naturaleza en contextos de pandemia", que organizamos en el Salón de Grados de la Facultad de Derecho de la Universidad de Sevilla el día 4 de julio de 2019, dentro del I Congreso Derechos Humanos y Globalización.

Por lo general, las mesas redondas que se celebran en los seminarios o congresos suelen perder su real sentido de lugar de diálogo, de saber escuchar, de intercambio de ideas y de discusión interactiva entre los miembros que la componen. Normalmente, cada integrante de la mesa realiza una especie de micro-conferencia unidireccional en la que cada uno suelta su discurso sin ninguna intención de debatir con los otros integrantes, y los oyentes se limitan a oír y, a veces, se les abre el turno de preguntas. Además, cuando alguien avisa que será breve, suele mentir y se explaya más de la cuenta, sin sentido de la limitación del tiempo. Para romper esa costumbre, Pilar Cruz Zúñiga y yo, decidimos recuperar el formato originario de lo que debe ser una verdadera mesa redonda. Pensamos que el moderador o la moderadora debían realizar una serie de preguntas sobre los pueblos indígenas, los derechos humanos y la globalización. Los miembros invitados debían contestar dialogando y conversando unos con otros, teniendo en cuenta un determinado tiempo razonable de intervención. En este caso, yo fui el moderador de la mesa de diálogo y los contertulios fueron Pilar Cruz Zúñiga, profesora de sociología en la Universidad Pablo de Olavide, Fernando Antonio de Carvalho Dantas, profesor especialista en pueblos indígenas en la Universidad de Goiás, Asier Martínez de Bringas, profesor de la Universidad de Deusto y Juan Carlos Cayo, abogado chileno asesor de pueblos indígenas. Todo se desarrolló dinámicamente, con agilidad, creativamente y teniendo al público bien entretenido. El director de esta revista, Ramón Soriano, que estuvo presente en la mesa redonda, me sugirió hacer un monográfico sobre lo debatido y, si era posible, con los mismos participantes. Todos aceptaron al principio, pero al final, solo tres han aportado sus trabajos al monográfico: Pilar Cruz, Fernando Antonio de Carvalho y Asier Martínez de Bringas. Lamentablemente, Juan Carlos Cayo Rivera no ha podido por el denso trabajo que tiene como asesor de algunos actores indígenas protagonistas del proceso constituyente chileno. Por esta razón le ha sustituido Antonio Salamanca, iusfilósofo cordobés y exprofesor del Instituto de Altos Estudios Nacionales de Ecuador (IAEN), quien, gentilmente, aceptó mandar su aporte.

Las preguntas planteadas ese día fueron seis y se situaron dentro del tema central del congreso. Al inicio, realicé una reflexión introductoria e interpeladora para los cuatro interlocutores y todos los presentes sobre cuál era el mundo o en qué mundo era en el que queríamos vivir con la Humani- 
dad y la Naturaleza, si en un mundo en el que cupiésemos tod@s, con calidad de vida digna, incluyente, o en un mundo en el que cupieran solo unos pocos, para una minoría privilegiada, excluyente junto con o sin la Naturaleza. Seguidamente iniciamos la discusión deteniéndonos con cada pregunta planteada escalonada y secuencialmente. Fueron estas:

1. ¿Qué papel pueden tener los derechos humanos en ese mundo que queremos, con sus luces y oscuridades? Comentar sus posibles rostros: su rostro emancipador y su rostro colonial como caballo de Troya del capitalismo.

2. Lo común como una propuesta de nuevo principio político ¿puede ser una salida, alternativa o límite a la dinámica del capitalismo corporativo y depredador? ¿Enfrenta el euro-centrismo y el occidentalo-centrismo de los derechos humanos y su cara colonial, patriarcal y racista? ¿Puede quebrar la cultural individualista propia de los derechos humanos en su versión liberal? ¿O es un simple maquillaje reformador y no transformador de la globalización capitalista?

3. Desde un punto de vista intercultural, ¿qué pueden aportar los pueblos indígenas y sus proyectos de vida, cosmovisiones y su modo de entender la lucha por la dignidad de cara a un mundo en el que quepan muchos mundos y desde procesos de reconocimiento de las diversidades incluyentes y no excluyentes?

4. El Buen vivir (Suma Qamaña, Ñandareco y Sumak Kawsay, entre otras propuestas) ¿podría interpretarse como un modo intercultural de entender lo común desde la diversidad cultural y la pluralidad de proyectos de vida que trazan caminos distintos de entender las relaciones humanas de forma colaborativa, solidaria, fraterna, comunal, de reconocimientos mutuos y en armonía expresa con la Naturaleza? ¿Cómo evitar el peligro de reducir conceptual y metodológicamente su significado a una dimensión occidental positivista y normativa?

5. ¿Qué repercusiones tiene la autonomía para los pueblos indígenas y su relación con la lucha política y la praxis de lo común visto desde miradas no occidentales?

6. ¿Qué consecuencias puede tener el reconocimiento de la Naturaleza como sujeto de derechos y, más en concreto, el reconocimiento judicial de los ríos como entidades sujeto de derechos biocultural tal como ha sucedido en Ecuador, Colombia, la India y Nueva Zelanda?

La riqueza y la profundidad de las intervenciones fueron y aportaron interesantes perspectivas a las cuestiones planteadas. En ese momento no se nos ocurrió realizar algo por escrito, pero, posteriormente, para el monográfico del RIPP sugerido por Ramón Soriano y que ahora presento, se les dio a todos los autores libertad y flexibilidad en el modo como querían realizar sus trabajos, teniendo presentes y de manera latente, los contenidos sugeridos por las cuestiones lanzadas en la mesa redonda. No tenían que desarrollar cada una de ellas de manera detenida o detallada, sino solo tenerlas en cuenta del modo como quisieran. El monográfico que ahora tienen ante sí los lectores es el resultado.

Por otra parte, entrando en sendas de contenidos más profundas, para presentar a modo de introducción los artículos de este monográfico, quisiera aludir a la metáfora deportiva que Erik Olin Wright retoma, en su libro Comprender las clases sociales (2018), dentro de la discusión que tiene con el concepto de "microclases" de David Grusky y Kim Weeden, 
quienes la emplean para construir un análisis de clases sobre la base de categorías ocupacionales que se encuentra en situación de alta desagregación. Salvando las distancias y sin intención de trivializar, yo la proyectaré sobre los artículos de este monográfico y su eje aglutinador de los pueblos indígenas, lo común, lo intercultural y los derechos humanos.

En concreto, Erik Olin Wright utiliza la tipología de luchas políticas en las sociedades capitalistas de Robert Alford y Roger Friedland, relacionadas con tres formas diferentes de poder: a) poder sistémico; b) poder estructural / institucional; y c) poder situacional. Para ello, los autores de The Powers of Theory: Capitalism, the State and Democracy, mencionan la metáfora de los juegos para explicar cada una de esos conflictos. Erik Olin Wright los proyecta sobre el mundo del deporte como recurso pedagógico y aclaratorio, partiendo de la premisa de que entiende la política como algo orientado a los diferentes niveles del juego que llamamos sistema social. Ello le sirve para intentar coordinar, en la medida de lo posible, las formas de análisis sociológico de clase marxistas, weberianos y durkheimianos:

a) La lucha de poder sistémico sería una lucha por establecer el juego que hay que jugar. En este caso, la lucha política entre revolución y contrarrevolución sería el ejemplo de una lucha acerca de cuál es el juego que debe realizarse. En la relación capital / trabajo, durante el siglo XIX y hasta la década de los años treinta del siglo XX, la disputa entre capitalistas, socialistas y comunistas se situaba en qué juego había que establecerse y en el que había que jugar: si el ofrecido por la clase trabajadora y su defensa de un modo de producción en el que los productores son propietarios de los productos, o el ofreci- do por la clase empresarial y defensora de un modo de producción expropiatorio del producto generado por el proletariado y, también, de un modo entender la propiedad privada en términos excluyentes y de exclusividad.

b) La lucha por el poder institucional, se centraría en las reglas del juego ya determinado. Las políticas de reformas y las políticas reaccionarias constituirían las luchas por las reglas del juego establecidas dentro del capitalismo. Tras el triunfo de las clases oligárquicas propietarias, un único juego se impuso, el del mercado capitalista, y únicamente había que moverse dentro de él, disputándose únicamente las reglas. Ahora, el conflicto se desarrolla entre las distintas fuerzas sociales propietarias y proletarias para establecer las reglas más adecuadas y más beneficiosas para cada clase o grupo social y, también, para regular la institución del Estado dentro del gran juego del mercado y del capital. Ya no hay posibilidades de establecer otro juego. Solo se puede jugar dentro de los tipos de regulación permitidos e impuestos por el capitalismo. En esta nueva situación, mientras los sindicatos tengan fuerza, algunas reglas podrán negociarse y establecerse con cierto margen de modificación y cambio. El papel del Estado será el de mediador de unos u otros, buscando consensos que favorecen más o menos a cada una de las partes.

c) Finalmente, las luchas sobre el poder situacional se ubicarían en los movimientos que, dentro del juego y sus normas, se pueden realizar. Aquí nos encontraríamos con las políticas de los grupos de interés en donde las luchas de las fuerzas sociales se empeñan en moverse, en función de sus intereses, dentro de las reglas fijadas y las normas establecidas que ya no se podían cambiar. Así como ejemplo, 
dentro de la hegemonía absoluta y globalizada del capitalismo, el margen de conflicto se redujo por parte del mundo del trabajo y los trabajadores únicamente a someterse a las reglas impuestas por el gran capital. Se podía jugar sin cuestionar ni las reglas del juego ni el juego en sí. No había otra opción. Los más listos, serían los que más partido sacarían a la lógica del sistema hegemónico.

Pues bien, a pesar de que Erik Olin Wright habla de las tres luchas sistémicas, institucionales y situacionales en términos de clase, creo que también pueden proyectarse sobre las luchas, demandas y reivindicaciones que, históricamente, los pueblos o naciones indígenas vienen realizando contra los excesos y perversidades producidas por la cultura occidental capitalista, ya que sus dinámicas de poder tácticas y estratégicas se mueven en todos los niveles. No obstante, en términos de sistemas de dominación, también la tipología trinitaria podría aplicarse sobre otros tipos o sistemas de sujeción como pueden ser el dominio patriarcal y el dominio colonial, considerando que todos suelen estar imbricados por la interseccionalidad. De todas formas, desde mi punto de vista, los cuatro trabajos del monográfico, por su modo de situar y analizar a los actores y los colectivos indígenas en el ámbito de los derechos humanos, lo común y lo intercultural, se pueden incardinar en los tres tipos de luchas políticas mencionadas, pero con matices. Cada uno resalta más un modo de lucha sobre el resto.

Por un lado, todos los artículos se refieren al hecho de que los pueblos indígenas con sus proyectos de vida y sus particulares sistemas de necesidades y capacidades, han jugado y juegan un juego distinto al que el capitalismo les quiere imponer y, en muchos casos, les impone.
Pese a formar parte del sistema social de los países americanos cuya pertenencia se sitúa dentro del capitalismo periférico y semi-periférico del sistema-mundo, son colectivos cuyas culturas, historias y formas de vida son anteriores a la llegada de los europeos al continente con el bagaje genocida y epistémico sufrido y acumulado hasta nuestros días. Por tanto, poseen "sus propios juegos de vida y de existencia", eso sí, re-significados para bien y/o para mal por la influencia de la cultura occidental capitalista, sin que ello impida múltiples y heterogéneas acciones estratégicas con las que intentan cambiar las reglas de juego. En este sentido, tal como dice Erik Olin Wright, un sistema social que constituye una sociedad no es una totalidad singular e integrada en la que todo encaja perfectamente, porque se parece más a un ecosistema flexible organizado en el que interactúan variedades de procesos contingentes y en donde se juegan múltiples juegos simultáneamente, sin que sea claro a veces la distinción entre un cambio de reglas o un cambio de un juego a otro. Por ello, en lo que toca a las sociedades multiculturales y con presencia indígena, los espacios y lugares en los que actúan los pueblos indígenas también se mueven en los distintos niveles de poder y utilizando tácticas y estrategias distintas y combinadas, siendo a veces difíciles de clasificar si son sistémicas, institucionales o situacionales. Los cuatro trabajos del monográfico, tal como he dicho, también expresan estas características.

En primer lugar, creo que los trabajos de Asier Martínez de Bringas y de Antonio Salamanca, reflejan muy bien la lucha sistémica de las naciones indígenas frente a las lógicas y dinámicas del capitalismo. Para ambos, la interculturalidad no es 
únicamente un problema de establecer las reglas de diálogo dentro del predominio mono-cultural de la tradición liberal e individualista, ni en función del particular sistema de necesidades y capacidades de la cultura occidental. Decía Raimundo Panikkar (1990) que nunca habrá una real pluralidad cultural si no hay un reconocimiento efectivo de la pluralidad en los modos de producción y de la diversidad económica. Muchas veces, se oculta esta realidad, generando una aparente sensación de respeto de la diversidad poniéndose solo el foco en lo simbólico e identitario, omitiéndose el soporte sociomaterial, socio-económico y existencial.

Si consideramos que el juego de vida de los pueblos indígenas se fundamenta en los derechos colectivos de auto-organización, autonomía política y jurídica, autogestión económica y cultural, junto con la titularidad y administración de sus propios recursos y territorios comunales, Asier Martínez de Bringas defiende que los comunes-indígenas son el núcleo desde donde entender el planteamiento de transformación y resistencia comunitaria de los pueblos indígenas y, además, funcionan como modelos alternativos coherentes que explican cómo se puede crear y sostener valor significativo fuera del sistema de mercado. Gracias a ellos, se des-mercantiliza la economía crematística capitalista que destruye el medio-ambiente por su egoísmo individualista, consumista y codicioso. Incluso el iusfilósofo vasco afirma que los comunes-indígenas son un modelo evolutivo, dinámico y funcional de autogestión y abastecimiento de recursos y formas de vida que combina modelos productivos, junto con prácticas socio-colectivas de vida y sociabilidades, en interdependiente tensión con relaciones culturales y espirituales con el territorio y sus diferentes formas vivientes. Aquí aparece la significancia de la Naturaleza y el reconocimiento de sus derechos que es expresión del sistema de vida basado en un bio-centrismo radicalmente opuesto al antropocentrismo abstracto, fetichista e idolátrico de la cultura occidental burguesa capitalista.

En la misma línea, Antonio Salamanca subraya que los comunes-indígenas manifiestan la estructura del sistema de necesidades y capacidades sobre el que basa el derecho de los pueblos y, en este caso, de los pueblos indígenas en armonía con la Naturaleza. Los satisfactores concretos creados por sus culturas y proyectos de vida, determinan la pluralidad de modos de especificar el sistema de necesidades y de capacidades que fundamenta la naturaleza humana y que no se reducen a los moldes establecidos por Occidente. El juego del capitalismo impone unos modos de entender el sistema de necesidades y capacidades común a la naturaleza humana, anulando los juegos distintos expresados en lo modos concretos que los indígenas desarrollan para satisfacer el sistema de necesidades y de capacidades que son especificados en función de sus contextos históricos, culturales y relacionales. Las comunidades indígenas y los pueblos con sus prácticas milenarias, acotan como bienes merecedores de especial protección para la producción y reproducción de la vida, las sociabilidades, entornos relacionales y tramas sociales basadas en el respeto por la Naturaleza y el vínculo armónico comunal, colectivo, fraterno y basado en el buen vivir, siendo muy diferente a los bienes y medios satisfactores de la cultura capitalista que priorizan los derechos individuales, junto con los dogmas del libre mercado, el crecimiento económico, la depredación del medioambiente y la competitividad. 
Tanto Asier Martínez de Bringas como Antonio Salamanca denuncian la política colonizadora, explotadora, ladrona y expropiatoria de la cultura occidental. Incluso, la capacidad que tiene el capitalismo de apropiarse de discursos y productos culturales de otras sociedades, abstrayendo, simplificando y amputando los heterogéneos significados, pone en peligro el sentido de lo común y el modo de entender a la Naturaleza como sujeto, al reducir sus ricos y complejos contenidos, traduciéndolos en términos cientificistas y mercantiles, además de colocar al Estado en el principal mediador que facilita sus intereses. El caso de la economía extractiva es un claro ejemplo y la dificultad que, incluso gobiernos progresistas, tienen para confrontarla pues terminan por aceptarla. Por ello, los dos autores defienden que los pueblos indígenas son los legítimos garantes y guardianes de la diversidad biológica y cultural, de toda una ecología de seres vivientes y no vivientes, de saberes y de epistemologías que van más allá de los intereses extractivistas que tanto daño hacen.

Un ejemplo del reduccionismo sesgado e ideologizado de los conceptos y de las instituciones, lo podemos comprobar en el principio de consentimiento previo, libre e informado que obliga a los estados y a otros actores del mundo mercantil, a contar siempre con el consentimiento de los colectivos indígenas antes de realizar cualquier tipo de acción en sus lugares de vida. Pese a que se pueda considerar positivo, el hecho es que en la mayoría de las ocasiones no se suele aplicar, quedando en papel mojado. De todos modos, soy de los que piensan que ese principio debería invertirse, en el sentido de que los pueblos indígenas son los que deben establecer las reglas de consulta que otorgarían a los estados y a las empresas para participar en los asuntos consentidos por las naciones indígenas, siendo ellas las que decidan cuándo y sobre qué se les da la palabra a sus interlocutores estatales y mercantiles. La decisión última sería la que los indígenas tomaran, no las hechas por los estados y sus aliados capitalistas.

En segundo lugar, el artículo de Fernando Antonio de Carvalho Dantas, aunque también tiene como trasfondo la lucha sistémica de los pueblos indígenas, se sitúa en las acciones estratégicas institucionales que éstos realizan en el ámbito jurídicoconstitucional para disputar las reglas de juego del capitalismo. El denominado nuevo constitucionalismo latinoamericano, tiene como finalidad última transformar la lógica del mercado y el sentido del Estado tradicionalmente subordinado a él, utilizando los medios constitucionales del derecho para enfrentar el horizonte monocultural y jurídico-monista, desde el reconocimiento de la diversidad cultural, la plurinacionalidad y el pluralismo jurídico.

De esta manera, las nuevas constituciones de Ecuador y Bolivia representarían el puente por el que conectar y unir las luchas sistémicas con las luchas institucionales, enfrentando las violencias históricas y estructurales sufridas y cuestionando el tratamiento desigual, asimétrico y destructivo de la cultura jurídica y política tradicionalmente ejercida contra ellos en América Latina. El nuevo constitucionalismo latinoamericano recupera el carácter demo-diverso y liberador de los derechos colectivos de los pueblos indígenas junto con los derechos de la Naturaleza. El reconocimiento constitucional de los proyectos de vida a partir de la multiculturalidad, la pluriversalidad, lo pluricultural, lo intercultural y la plurinacionalidad objetivan modos de ser, de saber-conocer, de hacer y de poder comunales, cuyos siste- 
mas de vida indígenas se sostienen en el buen vivir bio-céntrico y geocéntrico (p.e. el sumak kawsay andino, el suma qamaña aymara y el ñandereko guaraní). No se trata solo de disputar las reglas de juego, sino introducir la vigencia de otros juegos distintos al del capitalismo, por muchas dificultades que se presenten.

Finalmente, el trabajo de Pilar Cruz Zúñiga, se refiere principalmente a las luchas y las resistencias situacionales de las mujeres indígenas, en el marco y en el contexto de la expansión capitalista global y los conflictos socio-ambientales que provoca en los territorios indígenas con sus políticas desarrollistas y centradas en la acumulación por desposesión. Los costos sociales y ecológicos para las comunidades y la Naturaleza, incluido el cambio climático, son muy altos con motivo de la economía extractiva eco-cida. La historiadora quiteña describe los contextos de extrema violencia que sufren los pueblos indígenas debido a la explotación de los recursos naturales del gran capital, la apropiación intensiva en gran volumen y de alta intensidad para su exportación. Como reacción, nos encontramos con un acertado análisis de las experiencias situadas y complejas de las propias mujeres indígenas con las que, desde sus compromisos políticos y de liderazgos respaldados por sus organizaciones, sus cosmovisiones y sus luchas cotidianas, abren espacios que van construyendo reconocimiento, pese a los elevados riesgos que asumen por esos contextos tan adversos y violentos dominados por sujeciones y poderes paternalistas, machistas, racistas, clasistas y coloniales.

El daño histórico y estructural producido con el expolio de materias primas, las explotaciones mineras, de hidrocarburos, las madereras, los monocultivos, así como la concesión del agua de los ríos y la cons- trucción de grandes infraestructuras para el desarrollo industrial, turístico, urbano, portuario (los megaproyectos) por los estados y las empresas transnacionales, tiene su respuesta en múltiples procesos y experiencias de movilización, demandas, reclamaciones y luchas en América Latina que se construyen desde abajo, desde los márgenes y desde pueblos históricamente oprimidos, que con sus acciones y los apoyos solidarios que reciben cuestionan y también transforman -poco a poco- las realidades instauradas, en las cuales predomina como metas y valores fundamentales el progreso, el desarrollo y la obtención del máximo beneficio.

Pilar Cruz Zúñiga visibiliza, principalmente, las estrategias que las mujeres indígenas realizan dentro de las reglas de juego del capitalismo opresor, en los pocos y pequeños márgenes de libertad que se abren, incluso frente a los aparatos del Estado, que se manifiestan como brazos armados de las multinacionales y las grandes corporaciones extractivistas. Asimismo, la autora realiza un cuestionamiento de la insuficiencia que posee el concepto general y monocultural de derechos humanos que se utiliza oficialmente en Occidente, complementándola con una perspectiva compleja, socio-material, multi-garantista, intercultural y pre-violatoria de los derechos humanos. Cruz Zúñiga aúna las luchas y las multigarantías de las acciones, prácticas y relaciones cotidianas que las mujeres indígenas levantan para que la efectividad de los derechos humanos se ejecute no solo por medio de las instancia estatales, sino también a través de medios jurídicos de garantía de derechos no estatales (pluralismo jurídico) y la acción social y cultural organizadas desde las tradiciones y cosmovisiones indígenas (garantías socio-políticas). 
Para finalizar, me gustaría aludir al cuento del león, la becerra, la oveja y la cabra narrados primero por Esopo y, después por La Fontaine. El relato es el siguiente:

La becerra, la cabra y su hermana, la oveja, con un orgulloso y fiero león, señor del entorno, dicen que, en tiempo pasado, formaban una sociedad y pusieron en común las ganancias y las pérdidas. En los lagos de la cabra, un ciervo quedó atrapado. Una vez llegados, el león contó con los dedos y exclamó: "Somos cuatro para compartir la presa". Luego repartió en tantas partes el ciervo: tomó para él la primera en su calidad de Señor: "Debe ser para mí, dijo, y la razón es que me llamo León: a eso no hay nada que replicar; la segunda, por derecho, también es mía. Este derecho, ustedes lo saben, es el derecho del más fuerte; y por ser el más valiente y valeroso, aspiro a la tercera parte; si alguno de ustedes osa tocar la cuarta parte, antes lo estrangularé y en mis garras morirá. (La Fontaine, 2007)

Christian de Duve (Morin, 2003), refieriéndose al capitalismo y en el contexto actual de la globalización, afirmaba que la Humanidad había creado un monstruo pluricéfalo que amenaza con devorarla a ella y a todo el planeta. Lo que quiero expresar con el cuento es que siempre prima la ley del más fuerte, dentro del juego político y las relaciones de poder. En toda relación humana con voluntad de poder, hay leones. A nivel global y planetario, el león o los leones se unieron para convertirse en un monstruo de múltiples cabezas.

Utilizando el relato como pretexto, considero que todo estado de naturaleza, sociedad ideal o todo contrato social que forman parte de nuestros marcos categoriales fundantes y enraizados en la tradición occidental y ensalzados por el pensamiento moderno, busca el consenso de todos los miembros de una comunidad o sociedad, pero siempre oculta e invisibiliza la jerarquía y la estructura desigual sobre la que se articula. Con el león, la ternera o la becerra, la cabra y la oveja quiero subrayar el hecho de que, por lo general, en todo acuerdo las cartas están marcadas por parte de quien tiene el mando en gestionar el espacio y el tiempo de las reglas de juego que le interesa poner sobre la mesa. Dogmáticamente nunca dejará negociar aquellos intereses y derechos que considera irrenunciables y que todos deben aceptar. Si observamos, en el relato hay algo muy curioso: se reparte un ciervo entre un animal que es carnívoro y tres que son herbívoros, con una expropiación y un robo previo ya que el ciervo estaba en territorio de la cabra. Muchas veces las condiciones de un contrato son asimétricas, no son neutrales y objetivas, sino que están mediatizadas por el imaginario de quien tiene más poder o le interesa defender sus intereses. Pero no solo eso, siempre aparecen colectivos que quedan fuera del contrato, como ocurrió con las mujeres y las denominadas razas de color no blanco. Pues bien, esto es lo que ha sucedido y sigue sucediendo con los pueblos indígenas.

Con los cuatro trabajos de este monográfico tenemos un elenco de las luchas sistémicas, institucionales-estructurales y situacionales que las naciones indígenas vienen realizando en defensa de sus culturas, tradiciones, creencias, epistemologías y modos de vivir. Evidentemente, para hacerse fuertes y consolidarse, necesitarían articularse con otras luchas no capitalistas desarrolladas por movimientos sociales cuya finalidad es construir un mundo en el que quepan muchos mundos y en el que quepamos tod@s, con varios juegos de vida y no solo con un solo juego hegemónico y unipolar. Hacer que el 
monstruo pluricéfalo deje de ser carnívoro y pase a ser herbívoro como la becerra, la oveja y la cabra requieren múltiples estrategias que sepan enfrentar, no una sola de las cabezas, sino todas simultáneamente. Un primer paso para ello sería reconocer que los pueblos indígenas son los titulares y quienes deben gestionar y administrar sus territorios, entre otras razones, porque nadie mejor que ellos, por lo general, protegen la biodiversidad y el medioambiente, pese a los claroscuros que en todo lo humano podamos encontrar. Sus modos de vida, sus sistemas de necesidades y capacidades y sus satisfactores, junto con las sociabilidades basadas en lo común y lo comunal, la reciprocidad, el reconocimiento mutuo y la fraternidad, el modo de articular y trascender los derechos humanos desde el apoyo mutuo, las luchas anti-patriarcales, anticoloniales y de no mercantilizar crematísticamente la existencia humana y no humana, el respeto de la Naturaleza y el reconocimiento de sus derechos, etc., serían concreciones y ejemplos de que existe la esperanza y la realidad de que otro mundo más justo, digno y plural, es posible.

A pesar de que los indígenas son uno de los colectivos humanos que más ha sufrido y continúa sufriendo una vulneración sistemática de sus derechos en forma de genocidio y epistemicidio, a lo largo del tiempo han demostrado, pese a este drama, una aleccionadora capacidad de supervivencia, en donde el respeto y la conservación de la biodiversidad aparecen como garantía de la sobrevivencia de todo el planeta. Para ellos, la Naturaleza nunca ha sido un recurso natural, y siempre han tenido que enfrentar las tentativas de destrucción propias del colonialismo capitalista para preservar su mundo. La Naturaleza es indisociable de la sociedad, la tierra es la fuente y la raíz de sus culturas y sus cosmologías generalmente interpretan la realidad a partir de una interrelación de no superioridad del ser humano con la Tierra y los seres que la habitan. Por esta razón, no sería descabellado ni tampoco osado defender que sean ellos los titulares y gestores de la biodiversidad y de los bienes comunes que forma parte de lo que, denomino, como recreaciones, entornos o espacios comunes de la Humanidad. Incluso mejor sería hablar de una herencia local (de los cuidados, las obras y las recreaciones que los pueblos indígenas desarrollan en sus relaciones con la Naturaleza) que nos beneficiaría a tod@s (para la totalidad de la Humanidad) y con sus propias reglas de un juego no capitalista. Pero esto es un tema que ahora no voy a tratar.

\section{Bibliografía}

La Fontaine, Jean (2007). Fábulas de La Fontaine, Madrid, Atlas Editores.

Morin, Edgar (2003). El método. La humanidad de la humanidad, vol. V, Madrid, Cátedra.

Panikkar, Raimundo (1990). Sobre el diálogo intercultural, Salamanca, Editorial San Esteban.

Wright, Erik Olin (2018). Comprender las clases sociales, Madrid, Akal.

David Sánchez Rubio

Universidad de Sevilla, Sevilla, España dsanche@us.es 
